\title{
Morphogenetic Properties of Human Embryonic Cells: Aggregation of Dissociated Cells and Histogenesis in Cultured Aggregates
}

\author{
J. J. Cassiman and M. R. Bernfield ${ }^{[35]}$
}

Department of Pediatrics, Division of Developmental Biology, Stanford University School of Medicine, Stanford, California, USA

\section{Extract}

To test the hypothesis that the morphogenetic behavior of human embryonic cells can be characterized in vitro, human and mouse embryonic cells were compared by several variables which are thought to reflect morphogenetic cellular behavior. Trypsinprepared cell suspensions of human (8-12 weeks) and mouse (13-18 days) embryonic organs were analyzed for (I) initial rate of aggregation, (2) aggregate size, (3) histogenesis in aggregates derived from a single organ, and (4) segregation of cells according to tissue type within mixed aggregates derived from different organs.

The initial rate of aggregation followed strict first order kinetics for $40 \mathrm{~min}$ at $37^{\circ}$. The rate was identical $(P>0.05)$ for different cell types, for different ages of the same tissue, in the presence or absence of serum, and for mouse or human tissues. Aggregate size varied widely, regardless of the species, tissue type, or embryonic age. Thus, under the conditions employed, these variables are not worthwhile indices of morphogenetic cell behavior.

On the other hand, histogenesis in human or mouse aggregates derived from a single organ was tissue specific. Mixed aggregates of human and mouse cells of the same organ behaved identically as aggregates derived from a single species, which indicates that species specificity is expressed less than tissue specificity. Regardless of species, cells from different organs within a single aggregate segregated from one another according to tissue type, which demonstrates that human embryonic cells show tissuespecific morphogenetic behavior.

These findings confirm, for human embryonic cells, observations made with other species, that morphogenetic cell properties can be analyzed in vitro.

\section{Speculation}

Demonstration that human embryonic cells maintain morphogenetic properties capable of analysis in a defined system in vitro opens the way for the direct study of human morphogenetic mechanisms and of possible genetic and environmental influences. Readily available normal or abnormal mouse embryonic cells could be used in combination with human embryonic cells to experimentally examine the pathogenesis of human developmental defects. 


\section{Introduction}

Embryonic tissues can be dissociated into suspensions of single cells which can be made to reaggregate under appropriate conditions in vitro, reconstructing the dissociated tissue. The histologic architecture of the reconstructed tissue often reproduces with high fidelity the in situ organization of the cells, their specializations, and extracellular products [6, 18, 19]. Although this process of in vitro tissue reconstruction does not duplicate in vivo organogenesis, reaggregation of dissociated cells has been used in studies of morphogenesis since Wilson [22] observed that a complete sponge could be reconstructed from a single cell suspension. Recently, it has been shown that cells from tissues expressing genetically determined developmental defects reassemble in a manner which reflects the morphologic abnormality $[4,5]$. Thus, in vitro tissue reconstruction may allow normal and abnormal morphogenetic cellular behavior to be assessed in an indifferent environment under controlled, replicable conditions.

In vitro tissue reconstruction, as developed by Moscona [11], involves trypsin dissociation of the embryonic tissue, followed by incubation of the cell suspension in a swirling flask during which the cells collide and adhere, forming cell aggregates. During culture of the aggregates, the cells rearrange, yielding tissue-specific histologic patterns in isotypic aggregates (cells derived from a single tissue), or segregation of cell types called "sorting-out" in aggregates of mixed tissues (heterotypic aggregates). Cells of the same tissue from different species do not segregate from one another [10, 11], which demonstrates that species specificity is expressed less than tissue specificity.

The morphogenetic properties involved in cell aggregation and tissue reconstruction include adhesion, specific cell recognition, mobility, growth, change in cell shape, production of extracellular materials, and cell death [1]. Several methods have been developed for measurement of various components of the overall process [13], but it is unclear whether these are accurate assessments of morphogenetic cellular properties. To test the hypothesis that the morphogenetic behavior of human embryonic cells can be characterized in vitro, human and mouse embryonic cells were compared through several variables previously suggested to reflect morphogenetic cellular behavior. The variables examined were (1) the initial rate of aggregation, (2) aggregate size, (3) histogenesis in isotypic aggregates, and (4) sorting-out in heterotypic aggregates. The experimen- tal results show that initial rate of aggregation and aggregate size are either insensitive or nonspecific indices of morphogenetic cell behavior, that histogenetic and sorting-out, behavior of human embryonic cells are indistinguishable from that of mouse embryonic cells and that this behavior is identical in mixed combinations of homologous human and mouse cells. These findings demonstrate that the morphogenetic properties of human embryonic cells can be analyzed in vitro and that readily available normal or abnormal mouse cells can be used in combination with human cells to experimentally examine the pathogenesis of human developmental abnormalities.

\section{Materials and Methods}

\section{Source of Embryonic Tissue}

Human embryonic tissues were obtained from therapeutic abortions performed by vacuum aspiration between the 7 th and the 14 th week of pregnancy. Embryo age was estimated from the development of the extremities and the face and was correlated with the date of the last menstrual period and the size of the uterus at the time of the procedure. By these assessments, over $90 \%$ of the organs studied were from embryos between 8 and 10 weeks of age. Mouse embryonic tissues were obtained by dissection of $\mathrm{DBA} / 2 \times$ C57BL/6 hybrid embryos [23]. Embryo age was determined by the day of discovery of the vaginal seminal plug (day 0 ) and confirmed in embryos 14 days and younger by examination of external morphologic features and salivary gland development.

\section{Media and Solutions}

Hanks' balanced salt solution [24] was supplemented with $100 \mathrm{U}$ penicillin and $50 \mu \mathrm{g}$ streptomycin $/ \mathrm{ml}$. Basal medium eagle (BME) with Hanks' salts [24] was supplemented with $2 \mathrm{~mm}$ L-glutamine, $100 \mathrm{U}$ penicillin, and $50 \mu \mathrm{g}$ streptomycin $/ \mathrm{ml}$, and modified by replacement of $\mathrm{NaHCO}_{3}$ with $15 \mathrm{~mm} \mathrm{~N}$ tris(hydroxymethyl)-methyl2-aminoethane sulfonic acid (TES) and $15 \mathrm{~mm}$ $N$-2-hydroxyethyl piperazine- $N$-2-ethane sulfonic acid (HEPES) buffered at pH 7.5 [25].

For aggregation kinetics and for in vitro culture, the BME medium was supplemented with $10 \mu \mathrm{g} / \mathrm{ml}$ deoxyribonuclease I [26] and $0.4 \mathrm{~g} / 100 \mathrm{ml}$ glucose. Calciummagnesium-free Hanks' solution (CMF-Hanks') was buffered with TES and HEPES as in BME. Cells were trypsinized with a solution which contained $0.5 \%$ two times crystallized trypsin [27] in CMF-Hanks'. 


\section{Preparation of Cell Suspensions}

Immediately upon removal from the human uterus, the aspirate was washed with sterile normal saline. In no instance was the embryo intact, but in most instances unmacerated embryonic organs were readily identified. 'These were placed in chilled Hanks' solution containing 50\% fetal calf serum (FCS) and kept on ice until processing later the same day. Mouse embryos obtained by direct removal from the uterus were processed identically. Embryonic organs were transferred to BME supplemented with 50\% FCS and dissected free of extraneous tissue. The tissues were rinsed in CMF-Hanks', minced into small pieces, transferred to $12 \times 35 \mathrm{~mm}$ plastic tubes, and incubated in CMFHanks' for $10 \mathrm{~min}$ at $37^{\circ}$. The CMF-Hanks' was removed, $1 \mathrm{ml}$ trypsin solution added, and the incubation continued for another $10 \mathrm{~min}$. The trypsin solution was carefully removed and the fragments rinsed three times with $2 \mathrm{ml} \mathrm{CMF-Hanks'} \mathrm{before} \mathrm{adding} 1 \mathrm{ml} \mathrm{BME}$ (with or without $10 \%$ FCS) containing $10 \mu \mathrm{g} / \mathrm{ml}$ DNase. The fragments were disrupted into a cell suspension by fre quent pipetting through small bore Pasteur pipettes. Further procedures were done at $4^{\circ}$. The cells were centrifuged ( $400 \mathrm{~g}$ for $5 \mathrm{~min}$ ), resuspended in $2 \mathrm{ml}$ cold BME, filtered through a $20-\mu$ pore size nylon screen [28], and stored at $4^{\circ}$ before aggregation.

The cell suspension thus obtained consisted essentially of single cells. Cell viability, measured by trypan blue exclusion, was greater than $95 \%$ for mouse tissues and varied between $60 \%$ and $90 \%$ for human tissues.

\section{Aggregation Kinetics}

Quantitative aggregation studies were performed in plastic dishes $(35 \times 10 \mathrm{~mm})$ layered previously with 2 $\mathrm{ml} 1.5 \%$ noble agar. The agar prevents the adherence of cells to the substratum, a significant source of error, especially in serum-free medium. The cell suspension was diluted to $1 \times 10^{5}$ cells $/ \mathrm{ml}$ in serum-free $\mathrm{BME}$, and $3 \mathrm{ml}$ were added to the dishes which were placed on a gyrotory shaker with a $3 / 4$-inch orbital motion [29] in a dry incubator at $36^{\circ}$ and rotated at $74 \mathrm{rpm}$. At 5 - or 10 -min intervals, the contents of a dish were diluted with $17 \mathrm{ml}$ Isoton solution [30] and the single cells and very small clumps counted with a Coulter counter model $\mathrm{A}[30]$ equipped with a $100-\mu \mathrm{m}$ aperture and a lower threshold set at $6 \mu \mathrm{m}$. The mean of two counts was taken for each dish, and duplicate dishes were counted for each time point.

The best straight line, which related logarithm of the percentage of single cells to time of aggregation, was obtained by computer analysis. The linearity of the regression line was tested by $\mathrm{F}$ test at $P=0.05$, and the slope and SE were compared by Student's $t$ test at $P=0.05$.

\section{Histology}

For histologic studies, $3 \mathrm{ml}$ cell suspension diluted to $1-1.5 \times 10^{6}$ cells $/ \mathrm{ml}$ with BME containing $10 \%$ FCS was added to siliconized glass dishes $(30 \times 12 \mathrm{~mm})[31]$, which were rotated and incubated as described for the kinetic studies. Fresh medium $(2 \mathrm{ml})$ was exchanged at 48-hr intervals, and the aggregates were rotated for up to 2 weeks before fixing in Carnoy's solution. When cells from two different tissues were aggregated together, equal numbers of cells were mixed up to a total of $1-1.5 \times 10^{6}$ cells $/ \mathrm{ml}$ and the aggregates rotated for 4 days.

\section{Results}

Initial rate of aggregation, aggregate size, histogenesis in isotypic aggregates, and sorting-out in mixed aggregates were assessed in different tissues of 60 human embryos. All studies, except for the sorting-out experiments which required a large number of cells, were conducted on organs from single embryos.

\section{Initial Rate of Aggregation}

The number of single cells in embryonic cell suspensions decreases with time of rotation incubation. This reduction in single cells can occur by disruption, adhesion to the substratum, or incorporation into an aggregate. The decrease in single cell number was due exclusively to aggregate formation inasmuch as total cell number (free cells plus cells mechanically dissociated from formed aggregates) did not decrease during the 40 -min period of aggregation and since by microscopy, no cells were adherent to the substratum at the completion of the aggregation period.

Single cell suspensions prepared from human embryonic organs (brain, spinal cord, lung, kidney; 8-10week gestation) and from mouse embryos were assessed for their initial rates of aggregation. Best-fit regression lines for the number of single cells as a function of incubation time were computed for each cell suspension. Plots of log percentage of single cells versus time for the first 40 min of aggregation were linear (F test, $P>$ 0.05 for each point), which indicates that the aggregation rate followed strict first order kinetics for 40 min. Comparison of the mean slopes in the absence of serum for 10 human brains, 5 human spinal cords, and brains 
from 5 litters of 13-day-old mice by Student's $t$ test showed no significant differences $(P>0.05)$ in aggregation rate between the same organs from different individuals or litters, which allowed results to be pooled for further comparisons. These comparisons revealed that the presence or absence of serum does not affect the initial rate of aggregation and that human and mouse cells of similar type aggregate at identical rates (Table I, Fig. 1). Results too limited for accurate statistical analysis on human lung and kidney suggest no difference in aggregation rate between organs.

\section{Aggregate Size}

Densely packed aggregates were observed within 2-3 hr of rotation incubation in serum-containing medium. After 18-24 hr, duplicate dishes were examined for aggregate number and for size with a calibrated reticule. The number of aggregates per dish varied between 1 and 10 for brain cells and between 10 and 20 for the other cells; no difference was noted between mouse and human tissues. Aggregate size varied widely; in the same dish or in duplicate dishes aggregate diameter ranged between 0.2 and $1 \mathrm{~mm}$, regardless of the tissue type or embryonic age, with the exception that brain cells formed larger aggregates $(0.5-1.0 \mathrm{~mm})$. Aggregates formed in agar-layered dishes tended to be smaller and more uniform in size than those formed in glass dishes.

Table 1 . Rate of aggregation for different embryonic tissues

\begin{tabular}{|c|c|}
\hline Embryonic tissue ${ }^{1}$ & $\begin{array}{c}\text { Aggregation rate mean slope } \\
\pm \mathrm{SE} \times 10^{3} / \mathrm{min}\end{array}$ \\
\hline \multicolumn{2}{|l|}{ Serum free } \\
\hline Human brain $(10)$ & $4.0 \pm 0.4^{3}$ \\
\hline Human spinal cord (5) & $5.2 \pm 0.7$ \\
\hline 13-Day mouse brain (5) & $6.5 \pm 1.1$ \\
\hline 17-Day mouse brain (2) & $5.5 \pm 0.7$ \\
\hline 13-Day mouse limb (2) & $3.3 \pm 0.3$ \\
\hline \multicolumn{2}{|l|}{ Plus serum } \\
\hline Human brain (10) & $4.1 \pm 0.3^{3}$ \\
\hline 14-Day mouse brain (2) & $5.4 \pm 0.9$ \\
\hline 18-Day mouse brain (2) & $4.3 \pm 0.2$ \\
\hline \multicolumn{2}{|c|}{$\begin{array}{l}1 \text { The number of human embryos or mouse litters examined for } \\
\text { each organ is indicated in parentheses. Each organ was run in } \\
\text { duplicate. } \\
2 \text { Aggregation rate is expressed as the mean slope, which is } \\
\text { defined as the logarithm of the percentage of free cells removed } \\
\text { from the suspension per minute. These first order kinetics were } \\
\text { maintained for } 40 \text { min. The best-fit regression lines for each } \\
\text { organ were linear }(P>0.05) \text {. } \\
3 \text { Comparison of the mean slopes for each organ and age to that } \\
\text { for any other organ and age, and for serum free to plus serum by } \\
\text { Student's } t \text { test showed no differences }(P>0.05) \text {. }\end{array}$} \\
\hline
\end{tabular}

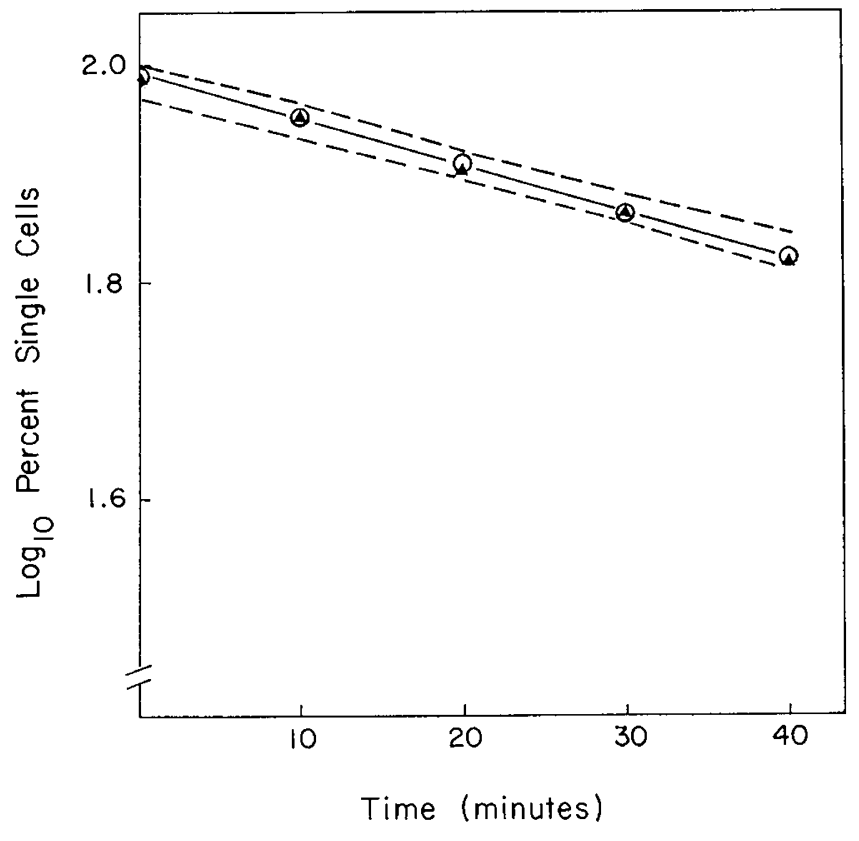

Fig. 1. Aggregation rate of human embryonic brain cells. The disappearance of single cells with time is expressed as the $\log _{10}$ percentage of free cells remaining in suspension at 10 -min intervals over the first $40 \mathrm{~min}$ of rotation-incubation. The best-fit regression line for 10 human brains in serum-free medium $(O)$ and for 10 human brains in serum-containing medium $(\boldsymbol{A})$ is represented with its $95 \%$ confidence limits (-- ). Similar lines computed for other human or mouse embryonic tissues fall within these $95 \%$ confidence limits and have a similar slope $(P>0.05)$.

\section{Histogenesis}

Human brain (30 embryos). To compare histologic pattern formation in aggregates with the in situ pattern, pieces (about $1 \mathrm{cu} \mathrm{mm}$ ) of human embryonic (8 weeks) telencephalon taken perpendicular to the neural canal were incubated as aggregates for 14 days. Histologic organization in these fragments was very similar to that seen in 14-day aggregates derived from dissociated whole brains of similar embryonic age (Figs. 2, 3,4 , and 5). In the lower power views (Figs. 2 and 4) groups of cell bodies are seen predominantly at the periphery. These groupings are separated by an extensive fibrillar network. At higher magnification, occasional mitoses can be observed and two cell types can be distinguished: one with high nuclear-cytoplasmic ratio and one with a low ratio. The fibrillar network and cellular organization in aggregates is not as extensive as in the control fragment. The histologic pattern in aggregates derived from 13-day mouse brain cultured for 14 days was virtually identical with that of the human brain aggregates.

Human spinal cord (15 embryos). Histologic organi- 

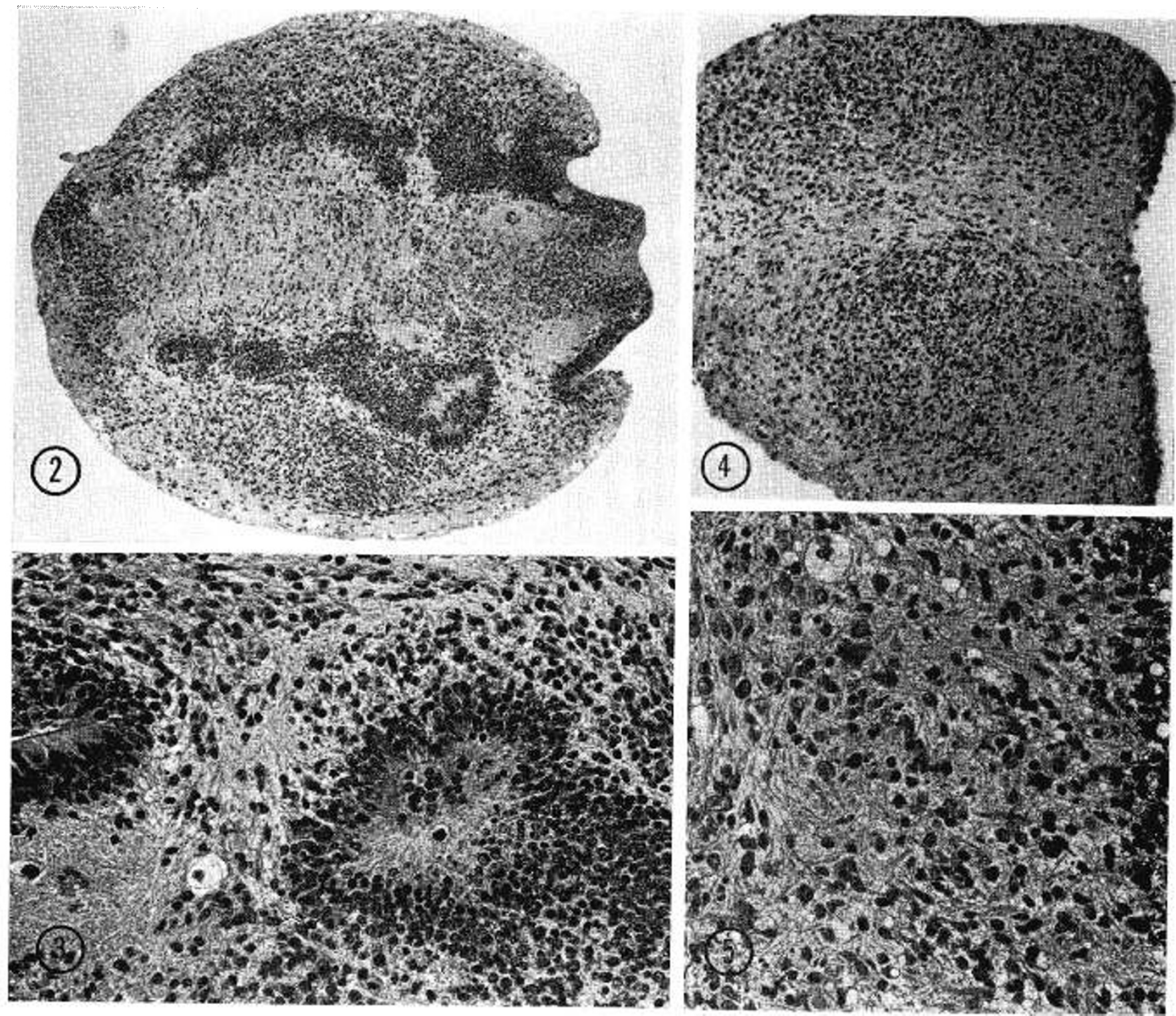

Fig. 2. Section through an intact fragment of an 8-week-old human embryonic telencephalon cultured for 14 days on the gyrotory shaker $(X$ 64). Note the symmetry in this fragment.

Fig. 3. High magnification ( $X$ 252) of fragment in Figure 2, which shows ependymal and neuronal cells surrounded by an extensive fibrillar network.

Fig. 4. Representative section of an aggregate derived from an 8-week-old human brain cultured for 14 days $\left(\begin{array}{ll}128\end{array}\right)$. Cell bodies concentrated at the periphery are separated from those in the center by a fibrillar network.

Fig. 5. Representative section at high power magnification of an aggregate derived from a 9-week-old human brain cultured for 14 days ( $\times$ 252). Cells with different nuclear-cytoplasmic ratios of neuronal, glial, and ependymal types are present. The cellular morphology and fibrillar network strongly resemble those in Figure 3, although there is no apparent orientation of the cells.

zation in spinal cord aggregates closely resembled the organization in brain cell aggregates. Cellular organization in both brain and spinal cord aggregates is clearly distinct from the organization of cells in aggregates from any other tissue.
Human lung (5 embryos). Aggregates of lung cells cultured for 4 days-1 week formed typical glandular structures which duplicated those seen in analogous mouse lung aggregates (Fig. 6). Loose mesenchymal cells surround groups of columnar epithelial cells, 


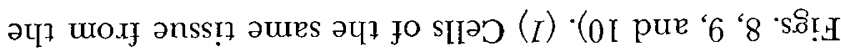

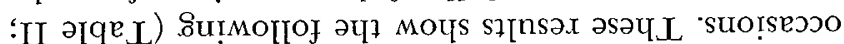

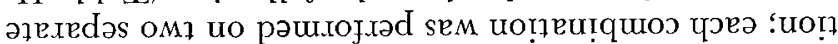

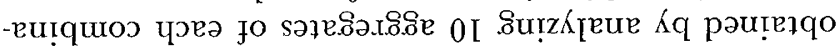

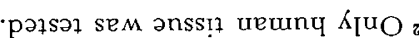

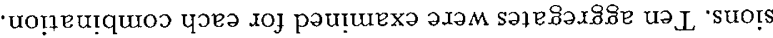

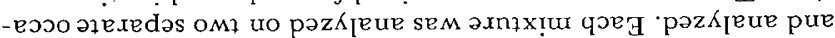

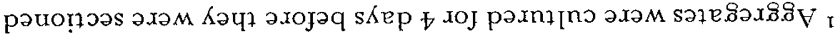

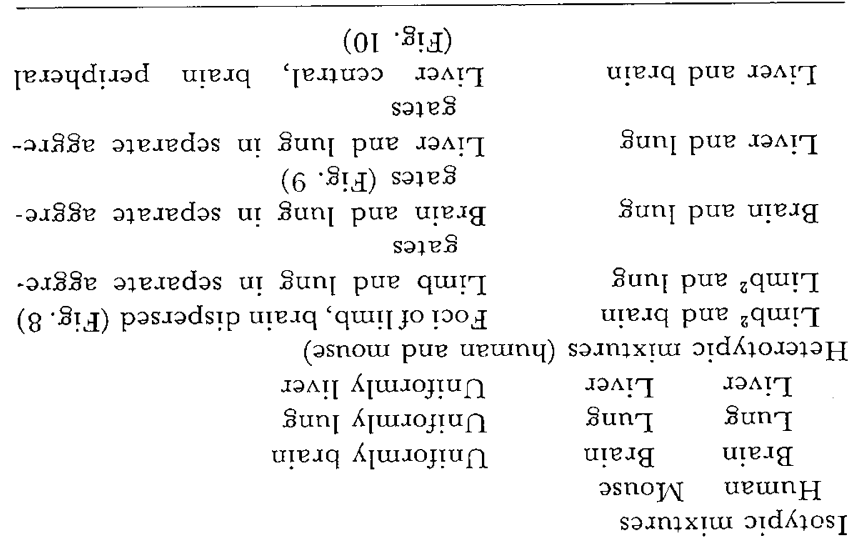

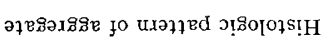

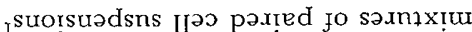

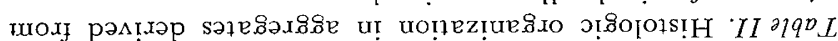

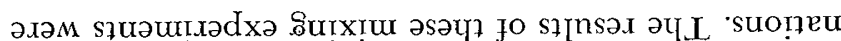

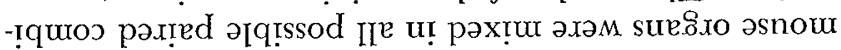

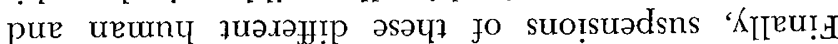

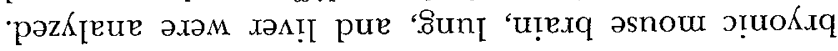

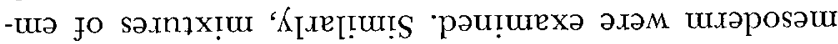

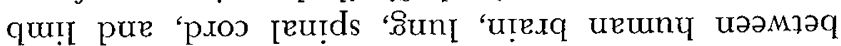

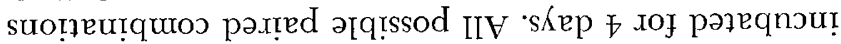

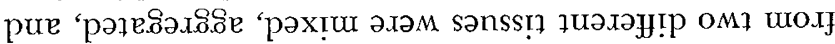

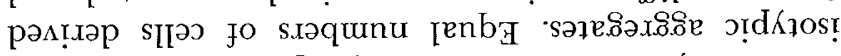

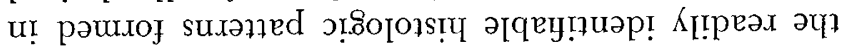

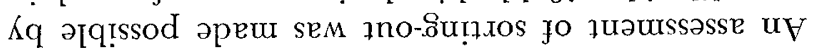

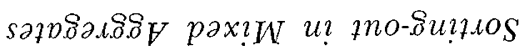

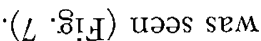

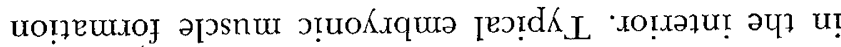

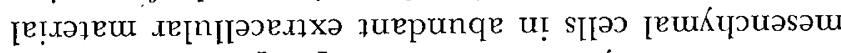

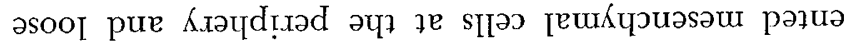

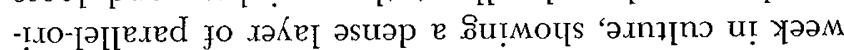

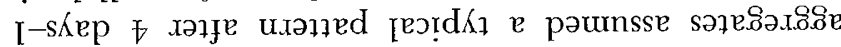

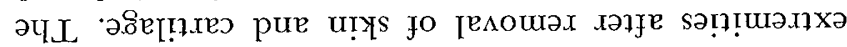

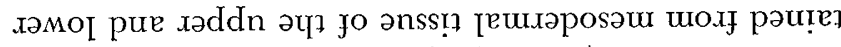

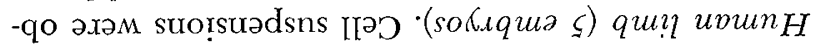

-UวəS SEM

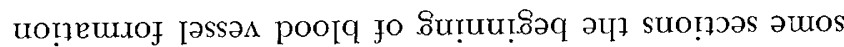

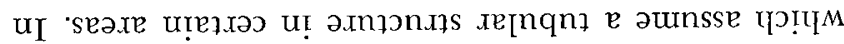

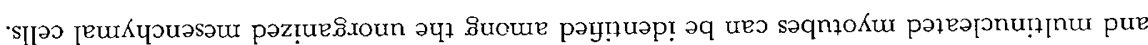

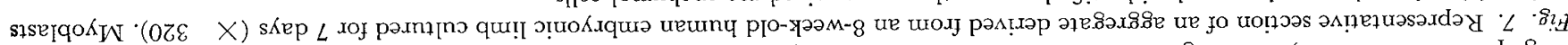

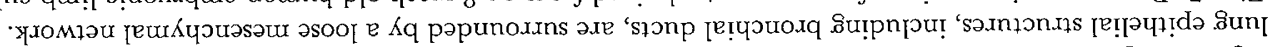

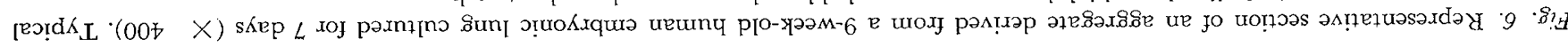
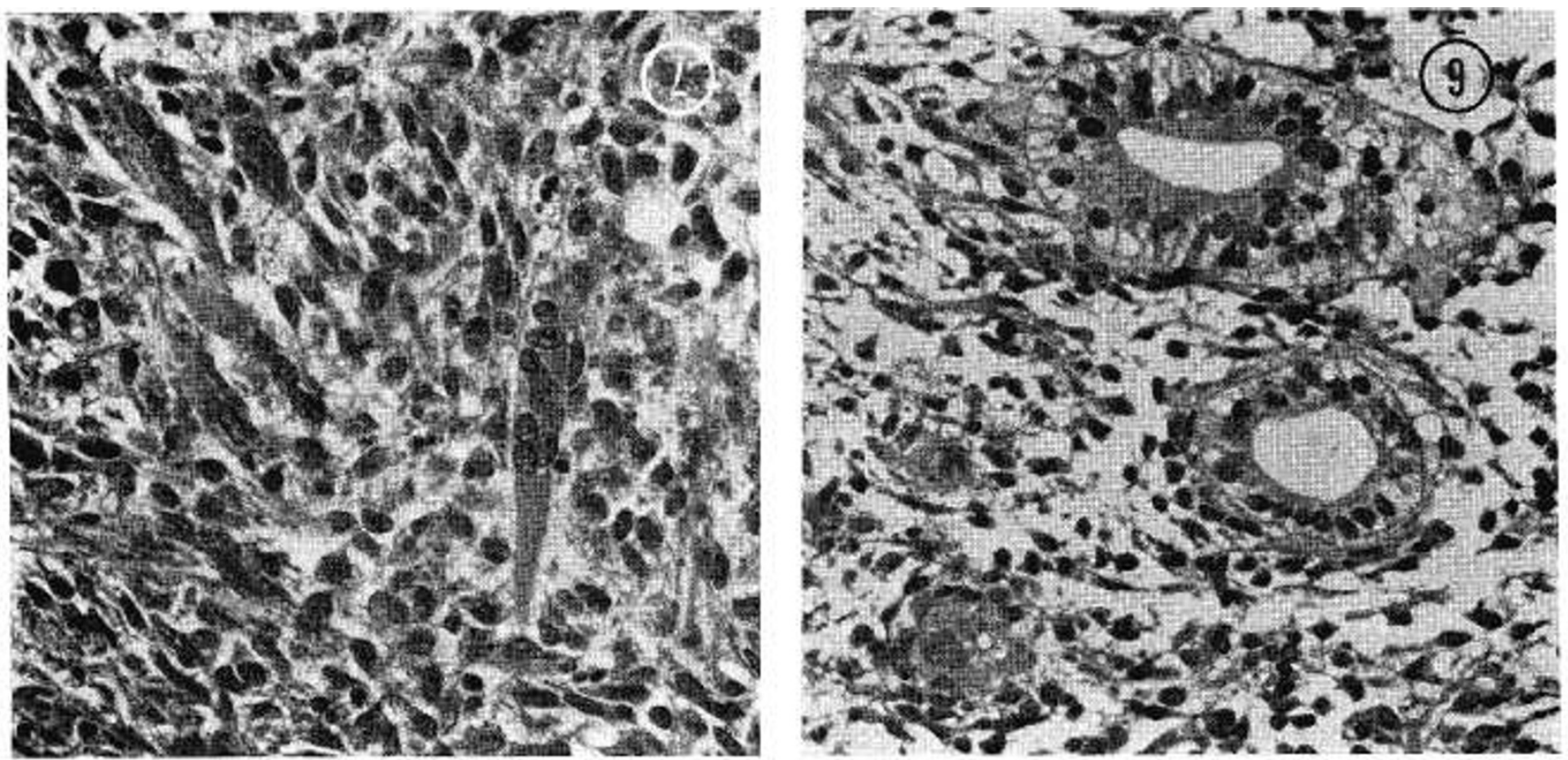

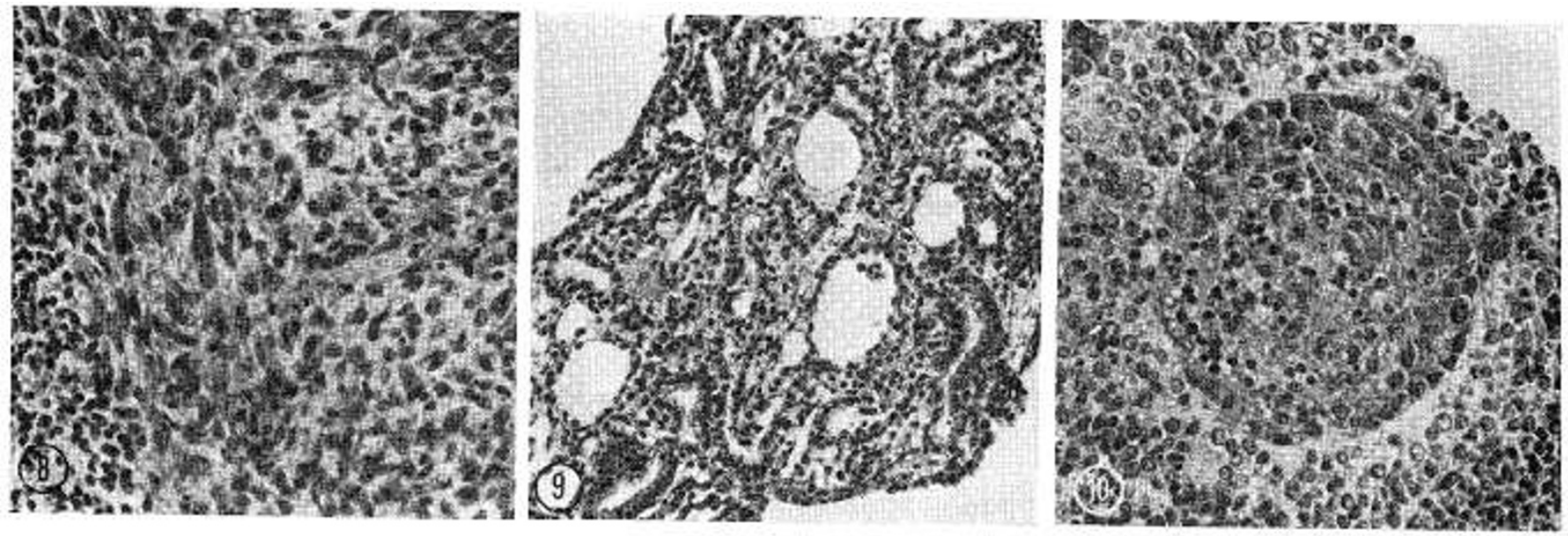

Fig. 8. Representative section through a 4-day-old aggregate obtained by mixing equal numbers of human 8-week embryonic brain and 9-week limb cells $(\times$ 252). The organization resembles that found in limb aggregates; multinucleated cells are clearly identifiable in clusters. Neural epithelial cells are scattered throughout the aggregate.

Fig. 9. Representative section through a 4-day-old aggregate obtained by mixing an equal number of human 9-week embryonic brain and mouse 13-day lung cells $(X 252)$. The histotypic organization of this aggregate is typical for lung tissue. Typical brain aggregates were found in the same dish.

Fig. 10. Representative section through a 4-day-old aggregate obtained by mixing equal numbers of mouse 13-day embryonic brain and liver cells ( $X$ 400). Large liver cells form clusters which are surrounded by neural epithelial cells.

two species did not segregate from one another: e.g., human brain and mouse brain; human lung and mouse lung. (2) Combinations of neural epithelial cells (brain with spinal cord) did not result in patterns that could be distinguished from brain or spinal cord aggregates. (3) Mixing of brain cells with lung cells resulted in extreme sorting-out in that only typical lung and brain aggregates were found in the same dish (Fig. 9). Similar results were obtained for other heterotypic mixtures of human mouse cells. (4) Aggregates of human or mouse liver cells with human or mouse brain cells showed clear evidence of sorting-out within an aggregate. The liver cells grouped in the center of the aggregates, and formed multiple small foci of liver tissue, which were easily distinguished from the neural epithelial cells which surrounded them (Fig. 10).

\section{Discussion}

The present study establishes that cells dissociated from 8- to 12-week-old human embryonic tissues reaggregate, undergo histogenesis in isotypic aggregates, and sort out in mixed aggregates in a fashion identical with mouse embryonic cells. Further, combinations of human and mouse cells of the same tissue type form "mosaic" aggregates which undergo histogenesis characteristic of the original tissue. Although this confirmation, for human embryonic cells, of prior observations made with embryonic cells of other species is not surprising, it provides a basis for the direct study of human mor- phogenetic cell behavior and of possible genetic and environmental influences on this behavior. Mouse cells of defined morphogenetic phenotype are readily available. Because human cells apparently share similar morphogenetic mechanisms, combinations of these cells with human cells may serve as a test system for detecting abnormalities in human morphogenetic cell behavior.

Measurements of the initial rate of cell aggregation and aggregate size reflect the degree of damage and recovery of the cells from tissue dissociation, the probability of adhesion after collision and the formation and strength of intercellular bonds, as well as experimental variables not intrinsic to the cells. In the present study, extrinsic factors were minimized by use of organic buffers to provide rigorous $\mathrm{pH}$ control, use of chemically defined media, inclusion of DNase to prevent interference by viscous glue-like DNA, and the use of agar-coated dishes to eliminate cell adhesion to the substratum. Under these conditions, aggregation reproducibly followed first order kinetics for $40 \mathrm{~min}$ at $37^{\circ}$ and rates were identical in the presence or absence of serum, which confirms the results of Orr and Roseman [14] on chick neural retina cells. However, initial aggregation rate and aggregate size were not worthwhile parameters for distinguishing morphogenetic cell properties. Identical aggregation rates were found for different cell types and for different ages of the same tissue, and, aggregate size (at 18-24 hr) varied widely even in the same or duplicate dishes. These results conflict with 
reports of tissue- and age-dependent differences in rate of aggregation (over several hours $[5,10]$ ), and aggregate size [6]. Possible explanations for the conflicting results include our use of whole organs consisting of various cell types, differing embryonic ages, and different aggregation conditions (time after trypsinization, buffer, agar coating, configuration, of vessel). Cell viability and variation in cell type are unlikely explanations since mouse cell suspensions had uniformly high degrees of viability and similar variation in cell type as in the prior studies.

Adhesion involves trypsin-susceptible surface components, which makes trypsin treatment and repair after trypsinization the most likely explanation. Our studies of initial rates were done before repair of trypsin-susceptible components. Proteolytic enzymes cannot be avoided, because chelators, such as EDTA (ethylene dinitrilotetraacetate, or Versene) will not completely dissociate these embryonic tissues [13]. The initial rate of cell aggregation and aggregate size may be useful indices of adhesivity, but under the conditions employed, these parameters are either too nonspecific or too insensitive to characterize cell properties responsible for determining final tissue architecture and organ morphology.

Although histogenesis and sorting-out in aggregates do not duplicate the process by which organs are formed in situ, the same morphogenetic mechanisms are involved [1, 10, 19, 20]. All of these mechanisms probably occur on or adjacent to the cell surface. Assays for components of the overall process have been reported [14-16], but the molecular events assessed in each method are unclear. On the other hand, several molecular phenomena have been proposed to account for cellular recognition, including tissue-specific aggregation enhancement factors [7-9, 12], surface glycosyl transferases and acceptors [17], genetically variable surface antigens [2, 3], and extracellular matrix materials $[9,12]$, but the role of these entities in morphogenesis is ill defined. Better defined methods for analyzing morphogenetic cell behavior and for relating diverse biochemical events to this behavior are needed. Development of these methods, together with the increasing availability of human embryonic tissues [21], should make possible the direct study of human morphogenetic cell interactions.

\section{Summary}

Initial rate of aggregation, aggregate size, the histotypic pattern and ability to sort out in mixed aggregates were assessed during rotation-mediated aggregation of cell suspensions obtained after brief trypsinization of different organs of 60 human embryos. The aggregation rate followed strict first order kinetics for $40 \mathrm{~min}$. Comparison of the mean slopes for 10 human brains, 5 human spinal cords, and brains from 5 litters of 13-day-old mouse embryos by Student's $t$ test indicated that no significant differences in aggregation rate existed between the same organs from different individuals or litters, that the presence or absence of serum does not affect the initial rate of aggregation, and that human and mouse cells of similar tissue type aggregate at identical rates. Aggregate size varied widely, regardless of the species, tissue type, or embryonic age. Histogenesis in aggregates derived from a single organ was tissue specific regardless of species. Although human and mouse cells of the same tissue did not segregate in mixed aggregates, sorting-out occurred in aggregates which contained human or mouse cells derived from different organs.

\section{References and Notes}

1. Bernfield, M. R., ANd Wessells, N. K.: Intra- and extracellular control of epithelial morphogenesis. Develop. Biol., Suppl. 4, $195(1970)$.

2. BODMER, W. F.: Evolutionary significance of the HL-A system. Nature, 237: 139 (1972).

3. Boyse, E. A., AND Old, L. J.: Some aspects of normal and abnormal cell surface genetics. Ann. Rev. Genet., 3: 269 (1969).

4. Delong, G. R., and Sidman, R. L.: Alignment defect of reaggregating cells in cultures of developing brains of reeler $\mathrm{mu}$ tant mice. Develop. Biol., 22: 584 (1970).

5. Ede, D. A., ANd Agerbak, G. S.: Cell adhesion and movement in relation to the developing limb pattern in normal and talpid ${ }^{3}$ mutant chick embryos. J. Embryol. Exp. Morphol., 20: 81 (1968).

6. Garber, B. B., and Moscona, A. A.: Reconstruction of brain tissue from cell suspensions. I. Aggregation patterns of cells dissociated from different regions of the developing brain. Develop. Biol., $27: 217$ (1972).

7. Garber, B. B., And Moscona, A. A.: Reconstruction of brain tissue from cell suspensions. II. Specific enhancement of aggregation of embryonic cerebral cells by supernatant from homologous cell cultures. Develop. Biol., 27: 235 (1972).

8. KurodA, Y.: Preparation of an aggregation-promoting supernatant from embryonic chick liver cells. Exp. Cell Res., 48: 626 (1968).

9. LrLIEN, J. E.: Specific enhancement of cell aggregation in vitro. Develop. Biol., 17: 657 (1968).

10. MosconA, A. A.: Cellular interactions in experimental histogenesis. Int. Rev. Exp. Pathol., 1: 371 (1962).

11. Moscona, A. A.: Rotation-mediated histogenetic aggregation of dissociated cells. Exp. Cell Res., 22: 455 (1961).

12. MosconA, A. A.: Cell aggregation: Properties of specific cellligands and their role in the formation of multicellular systems. Develop. Biol., 18: 250 (1968).

13. MosconA, A. A.: Cell aggregation. In: E. Bitar: Cell Biology in Medicine, p. 571 (Wiley Interscience, New York, 1973).

14. OrR, C. W., AND Roseman, S.: Intercellular adhesion. I. A 
quantitative assay for measuring the rate of adhesion. J. Membrane Biol., 1: 109 (1969).

15. Roth, S. A., And Weston, J. A.: The measurement of intercellular adhesion. Proc. Nat. Acad. Sci. U. S. A., 58: 974 (1967).

16. Roth, S., McGuire, E. J., ANd Roseman, S.: An assay for intercellular adhesive specificity. J. Cell Biol., 51: 525 (1971).

17. Roth, S., McGuire, E. J., and Roseman, S.: Evidence for cellsurface glycosyltransferases. J. Cell Biol., 51: 536 (1971).

18. SEEDS, N. W.: Biochemical differentiation in reaggregating brain cell cultures. Proc. Nat. Acad. Sci. U. S. A., 68: 1858 (1971).

19. Steinberg, M. S.: Does differential adhesion govern self-assembly processes in histogenesis? Equilibrium configurations and the emergence of a hierarchy among populations of embryonic cells. J. Exp. Zool., 173: 395 (1970).

20. Townes, P. L., And Holtraterer, J.: Directed movements and selective adhesion of embryonic amphibian cells. J. Exp. Zool., 128: 53 (1955).

21. Supreme Court of the United States, Opinion on the Cases of: (1) Roe et al. versus Wade, District Attorney of Dallas County, Texas; (2) Doe et al. versus Bolton, Attorney General of Georgia et al. (decided January 22, 1973).

22. Wrison, H. V.: On some phenomena of coalescence and regeneration of sponges. J. Exp. Zool., 5: 245 (1907).
23. Simonson Laboratories, Gilroy, Calif.

24. Grand Island Biological Co., Berkeley, Calif.

25. Nutritional Biochemical Corp., Cleveland, Ohio

26. Worthington Biochemical Corp., Freehold, N. J

27. Sigma Chemical Co., St. Louis, Mo.

28. Nytex, Ernst Tobler Co., New York, N. X.

29. Model G-2, New Brunswick Scientific Co., New Brunswick, N. J.

30. Coulter Electronics, Haileah, Fla.

31. Bellco Glass, Inc., Vineland, N. J.

32. The invaluable assistance of Ms. Jane Matthews is gratefully acknowledged.

33. Dr. J. J. Cassiman is Aangesteld Navoser of the "Nationaal Fonds voor Wetenschappelÿk Onderzoek," Department of Human Genetics, St. Rafael Ziekenhuis, Leuven, Belgium.

34. This research was supported, in part, by a grant from The National Foundation-March of Dimes and prepared while Dr. M. R. Bernfield was a John Simon Guggenheim Memorial Foundation fellow.

35. Requests for reprints should be addressed to: M. R. Bernfield, M.D., Department of Pediatrics, Stanford University School of Medicine, Stanford, Calif. 94305 (USA).

36. Accepted for publication October 25, 1973. 